Murmurations:

Journal of

Transformative

Systemic

Practice

\title{
Where did the Eco go in systemic practice?
}

\author{
Hugh Palmer
}

\section{Volume 4}

Issue 1

Winter 2021

Keywords:

Gregory Bateson,

ecology,

EcoSystemic

Return,

systemic therapy,

systemic practice,

posthuman,

systemic activism

Citation Link

\section{Abstract}

In this paper, I argue that, although the systemic therapy community adopted some of Gregory Bateson's ideas, we neglected his ecological concerns, and his thinking about epistemology and ontology might have shaped our practice even more than the comparatively few concepts we took. With rising concerns about the impact of humans upon the environment in the era in which we live, described as the Anthropocene, along with the posthuman turn, perhaps now is the time for us to look both backwards and forwards to deepen our understanding of Bateson's message; to acknowledge the continuing importance of his thinking and influence upon the posthumanities.
Now mind is clear
as a cloudless sky.
Time then to make a
home in wilderness.

A Desolation by Allen Ginsberg

\section{Introduction}

In September 2017, at an Association for Family Therapy Conference, I went for a walk in the woods in the grounds of the conference venue hotel in Dunblane, Scotland. It was early autumn, and the trees were beginning to show their golden colours. This was no ordinary walk but a contemplative, meditative walk in nature led by Lorna Edwards, a family therapist from Wales. It was a fascinating and delightful experience, and I was grateful to Lorna for helping me reconnect systemic thinking with ecology, nature and my relationship with the natural world. In a sense, we continue that walk together, remaining friends and, along with others, contributing to the development of an EcoSystemic Practice Network. 
This paper began life as a presentation for the inaugural EcoSystemic Return workshop and networking event held by the EcoSystemic Practice Network Movement in June 2021. My intention in this paper is to revisit Gregory Bateson's legacy, to consider what we might reclaim as part of our heritage, inform future practice, and discuss how more recent thinkers can support this move.

Most systemic practitioners will be aware of the significant contributions that Gregory Bateson made to the development of systemic family therapy. His early ideas, despite being reified at times, about communication patterns in families were instrumental in inspiring clinicians to work with families rather than with individuals. His later contributions such as taking a second-order position or the concept of circularity which was embraced by the Milan team, proved to be very influential and are still valued and integral elements of contemporary systemic practice. Nevertheless, the systemic community neglected much of his broader thinking. Bateson's more general ecological concerns and his thinking about epistemology and ontology might have shaped our practice even more than the comparatively few adopted ideas. With rising concerns about the impact of humans upon the environment in the era in which we live, now described as the Anthropocene era, along with the posthuman turn (Braidotti 2019), perhaps now is the time for us to look both backwards and forwards to deepen our understanding of Bateson's message, to acknowledge the continuing importance of his thinking and influence upon the posthumanities.

\section{Looking back to Bateson}

I believe that Bateson held hopes that therapists might be amongst those most open to his ideas and that we might be encouraged to work and think beyond the confines of the clinic and the family. As a relatively new profession, informed by his thinking, we seemed receptive to his cybernetic epistemology. Speaking at a 1969 Conference on Mental Health in Asia and the Pacific, he directly addressed therapists:

It is clear now to many people that there are many catastrophic dangers which have grown out of the Occidental errors of epistemology. These range from insecticides to pollution, to atomic fallout, to the possibility of melting the Antarctic ice cap. Above all, our fantastic compulsion to save individual lives has created the possibility of world famine in the immediate future.

Perhaps we have an even chance of getting through the next twenty years with no disaster more serious than the mere destruction of a nation or group of nations. I believe that this massive aggregation of threats to man and his ecological systems arises out of errors in our habits of thought at deep and partly unconscious levels.

As therapists, clearly we have a duty.

First, to achieve clarity in ourselves; and then to look for every sign of clarity in others and to implement them and reinforce them in whatever is sane in them.

And there are patches of sanity still surviving in the world. Much of Oriental philosophy is more sane than anything the West has produced, and some of the inarticulate efforts of our own young people are more sane than the conventions of the establishment

(Bateson, 1972, pp. 492-3) 
Reading this stark warning in 2021, I think of Greta Thunberg and her "Skolstrejk för klimatet" and the international Extinction Rebellion movement, perhaps voices of sanity in the face of the insanity of capitalism and necropolitics (Mbembe, 2003) and I both wonder if and hope that they offer the kind of clarity that Bateson asked us to seek. There are a handful of therapists who have heeded Bateson's call, but not many, and certainly not in the early days of our profession.

Having spent a considerable amount of time looking for early family therapists who may have written about ecology in the earlier days of family therapy (the 1960s-80s), only one family therapist, Edgar Auerswald, seemed to appreciate Bateson's message at that time, recognising that family therapists might begin to think differently:

Yes, I do believe that we all must learn to think like ecologists. My belief is born of the conviction that U Thant [Secretary-general of the United Nations from 1961 to 1971] is probably correct when he estimates that we have at most ten years before the point of no return will be reached in our headlong rush toward extinction. If there is the slightest chance that he is correct, and if we cannot manage to get the parents of our day to understand the cry of their children, it is just possible that our interest in families may become, not just academic, but horribly irrelevant. While none of us has the power to change the thinking style of the world, we can by our own thinking and our everyday operations promote and contribute to such crucial change. For the sake of our children, I believe we must do so, so that they may have children, too

(Auerswald, 1971, p. 7)

Auerswald stressed the importance of therapists taking personal responsibility to change their way of thinking and promote change, otherwise, our work with families would become irrelevant in the face of environmental collapse. Yet, despite his position of influence, few followed in his footsteps until decades later. One of the more recent voices is that of Tracy Laszloffy, a family therapist based in Connecticut, who has been promoting an ecosystemic approach for some time, noting that the field of family therapy has "devoted sparse attention to addressing the connections between individual, family, and environmental issues" (2009, p. 223). She has recently published an article (Laszloffy \& Davis, 2019) and a book (Laszloffy \& Twist, 2019), all of which contribute to the reclamation of Bateson's broader ecological concerns within systemic therapy.

Apart from Auerswald, who made a connection between our practice and broader ecological awareness and responsibility (e.g. 1968, 1971, 1987), it is evident that the early use of the term "ecosystemic" was restricted to thinking about the context of an individual within a family, and occasionally, their community. Thus, to early family therapists, the "ecology" was, in effect, the client's family and immediate network. This limited view of ecology was also evident in Neuro-Linguistic Programming, which shared some of the same roots as family therapy, emphasising developing a "well-formed, ecological outcome" with clients. But, again, the ecology here refers to the client's immediate context.

I have noticed a parallel in the writing of Arne Naess (2008), who contrasted deep ecology with shallow ecology. Shallow ecology focuses on short-term, narrow human interests, whereas deep ecology decentres humans and has ethical values respecting nature and the inherent worth of other beings. Bateson asked us to embrace a deep ecology. We didn't. 


\section{Not just another "gadget"}

Despite the relatively limited ecological perspective in family therapy, it is only fair to recognise that other elements of Bateson's thinking were adopted, enabling a shift from an anti-contextual and reductionistic epistemology concerned with objectivity and "truth" to a worldview encompassing complexity, contextual patterns of relationship and multiple realities. It could be argued that this was far more than another "gadget" (Bateson 1972, p. 150), as the shift to second-order thinking was (and still is) transformational.

In most of his writing, Bateson was critical of the conscious purpose characteristic of Western, lineal thinking and our lack of systemic wisdom in considering the broader implications of our actions. He used language, concepts, and metaphors drawn from his own experience as an anthropologist and natural historian. His thinking spanned what might now be called constructivist, social constructivist and social constructionist, suggesting that individuals build knowledge through a recursive relationship between cognitive processes and social interaction. His cybernetic epistemology does not allow for a duality of either/or between cognitive processes and social interaction; it is all one thing. Bateson considered that our perceptive processes are necessarily unconscious, which enables us to have a sense of "self" - so how you and I know what we know, then, is a process mediated by our (largely unconscious) perception of our cognitions, relationships and the context in which we live. Our knowing is in part self-referential (individually and collectively) and based upon unconscious, conscious, relational and contextual processes. Knowing, according to Bateson, is both epistemological and ontological.

His critique of Western (Occidental) thought (or epistemology) was a constant theme in his writing, warning that we are heading towards catastrophe unless we change the way we think. Bateson considered that our epistemology governs how we adapt to and construe our world, and it was clear that he was very concerned:

If we continue to operate in terms of a Cartesian dualism of mind versus matter, we shall probably also continue to see the world in terms of God versus man; elite versus people; chosen race versus others; nation versus nation; and man versus environment. It is doubtful whether a species having both an advanced technology and this strange way of looking at its world can endure

(Bateson, 1972, p. 343)

These words ring even more true today. For example, our advanced technology can connect people globally and create communities and at the same time increase division and polarisation. Our reliance upon, and intimacy with, technology has changed us, our relationships with each other and the material world. The cost to the environment of this advanced technology is high; the resources and materials required to manufacture mobile phones, computers or the latest electric cars have implications for the planet and human lives. Capitalism seems to be the zenith of a dualistic way of thinking that sees the Earth, creatures and humans as mere resources to be exploited for profit. We are now witnessing an elite where billionaires are sending themselves to space, and at the same time, people are starving, even in comparatively wealthy countries.

Bateson reminds us that, due to our dualistic epistemology and conscious purpose, we are destroying the very ecology of which we are a part: 
There is an ecology of bad ideas, just as there is an ecology of weeds [...] When you narrow down your epistemology and act on the premise 'What interests me is me, or my organisation, or my species,' you chop off consideration of other loops or the loop structure. You decide that you want to get rid of the by products of human life and that Lake Erie will be a good place to put them. You forget that the eco-mental system called Lake Erie is part of your wider eco-mental system-and that if Lake Erie is driven insane, its insanity is incorporated in the larger system of your thought and experience

(Bateson, 1972, p. 492)

As a discipline, I wonder if we have been guilty of contributing to this insanity, this ecology of bad ideas, by only focussing on the "bits" of Bateson's theories that interested us and chopping off the rest? Of course, the message in the quote above is much broader: our tendency to seek short-term solutions to problems without considering the wider implications of those choices demonstrates a lack of humility and wisdom. The impact of our choices upon our environment (or eco-mental system) will ultimately affect our own species, so when Lake Erie is driven insane, this insanity becomes part of us and our thinking. Nearly fifty years on, the entire planet is becoming insane. Wildfires are raging in the United States, Russia, Canada, Greece, Algeria, Turkey and Italy. Deadly and catastrophic floods have occurred in Europe. The Intergovernmental Panel on Climate Change (IPCC) released their sixth assessment report in August 2021, warning that "It is unequivocal that human influence has warmed the atmosphere, ocean and land. Widespread and rapid changes in the atmosphere, ocean, cryosphere and biosphere have occurred" (SPM-5).

Returning to therapists only focussing on elements of theory that were of immediate interest, and disregarding the wider contextual loops, Bateson was astute enough in his understanding of clinicians to warn us that:

Theory is becoming available to action oriented people, whose first impulse is that which is primarily in empiricism. 'Take it on the wards and try it. Don't waste years trying to understand the theory. Just use whatever hunches seem to follow from it.' Such people are likely to be frustrated and their patients hurt...Theory is not just another gadget which can be used without understanding

(Bateson, 1991, p. 150)

This sharp criticism was directed towards those who had reified the Double Bind Theory of schizophrenia (Bateson, Jackson, Haley, \& Weakland, 1956), including some of his then collaborators, and also towards those who interpreted it as if it were a theory of the "causes" of schizophrenia, possibly (according to the superficial understanding of the critics) blaming mothers, something that would be antithetical to Bateson. However, a lack of appreciation of theory can be apparent in our field. I have witnessed systemic practitioners who are quite capable of thinking systemically about the families they work with and yet appear incapable or unwilling of thinking systemically in contexts beyond the clinic, or even within the clinic itself.

For example, some systemic practices, like reflecting teams, can become ritualised gadgets, delivered without critical thinking about how, when, and where they are used. In their defence, many systemic practitioners work in rigid organisational structures that do not promote systemic thought beyond the clinic. Even the clinic itself is still primarily seen as the place to "do" therapy, rather than considering 
other spaces. I wonder how many of us switch off our "systemic" brains and revert to a non-cybernetic epistemology in our everyday lives. Bateson did acknowledge how hard (and isolating) it is to maintain a cybernetic epistemology in a dualistic world:

From time to time I get complaints that my writing is dense and hard to understand. It may comfort those who find the matter hard to understand if I tell them that I have driven myself, over the years, into a 'place' where conventional dualistic statements of mindbody relations - the conventional dualisms of Darwinism, psychoanalysis, and theologyare absolutely unintelligible to me. It is becoming as difficult for me to understand dualists as it is for them to understand me

(Bateson, 1977 p. 236)

Returning to cybernetic epistemology, Bateson explains how important it is to try to understand the larger circuits relevant to a particular context or phenomenon, and this quote is pertinent to our discussion of systemic therapy and the broader contexts of our practice:

The basic rule of systems theory is that, if you want to understand some phenomenon or appearance, you must consider that phenomenon within the context of all completed circuits which are relevant to it [thinking this way] might even lead the human race to a sort of wisdom that would preclude the wanton destruction of our biological environment and preclude some of the very peculiar attitudes we exhibit toward patients, foreigners, minorities, our spouses, and our children-and even each other

(Bateson, 1991, p. 260)

Narrative and more systemic therapists nowadays do pay more attention to the wider circuits of the lives of those they work with, from social justice issues in their practice, challenging oppressive dominant discourses and raising awareness of ecological problems, which is very encouraging. Still, there is much more that can be done to avoid focusing on single wider circuits.

As systemic thinkers and practitioners, we have a responsibility, not only to those we serve but also to ourselves, families, communities, and future generations. Bateson asked us to think beyond the clinic. We must. We are facing a multi-faceted crisis right now: inequality, pandemic, oppression and catastrophic climate change. Gail Simon recently referred to this as a "Panmorphic Crisis":

...the cluster bomb of social, health, climate and economic catastrophes, mass systemic failure over time and in the moment. I am using the term panmorphic crisis to describe a transitional time-space populated by urgent needs for changes in meta matters and materialities. And woven through this panmorphic crisis is a tussle between different epistemologies of control

(Simon, 2021, p. 20)

This crisis requires shifts in both our practice and our thinking, and these shifts are already beginning to emerge as rhizomatic, as points of growth and change (Deleuze and Guattari, 1987). I will explore some of these in the next section. 


\section{Looking forward: Posthumanism following Bateson's footsteps}

Valerie Featherstone (an educationalist, rather than a therapist), in her feminist critique of family therapy, wrote about a possible paradigm shift within our field that could be feminist and ecosystemic:

In a feminist ideological framework, life is an evolving process and is seen in multidimensional terms, thus there is 'no grand cure or final fix' for presenting problems...Therefore, it is considered that yet another paradigm shift could take place within family therapy, a feminist, ecosystemic, or ecological perspective and way of thinking being a preferable model when helping families

(Featherstone, 1996, p. 19)

Posthumanism (Braidotti, 2019) is a rejection of Cartesian duality made by Bateson, though not always attributed to Bateson, whom Deleuze and Guattari dismissed for his 'American career' (Shaw, 2015). The posthuman decentres humanity, challenging the narrative of boundaries between humans and other species, and even the material world, including natural and manufactured objects. Simon and Salter have framed the relationship between human and all other life-forms as transmateriality and shown how we create material-discursive worlds (Simon and Salter, 2019). But, again, Bateson had already laid the foundations for this in his analogy of the blind man and a stick, for example:

Consider a blind man with a stick. Where does the blind man's self begin? At the tip of the stick? At the handle of the stick? Or at some point halfway up the stick? These questions are nonsense, because the stick is a pathway along which differences are transmitted under transformation, so that to draw a delimiting line across this pathway is to cut off a part of the systemic circuit which determines the blind man's locomotion

(Bateson, 1972, p. 324)

Here, the stick is not a boundary but a pathway, illustrating Bateson's understanding of immanence that there are no "parts" or boundaries, only the system as a whole. Bateson could easily be described as a posthumanist. He asked us to think systemically about ourselves, our own lives and responsibilities, to each other and our environment, for we too are part of the whole. The feminist philosopher and physicist, Karen Barad, echoes this call:

We are responsible for the world of which we are a part, not because it is an arbitrary construction of our choosing but because reality is sedimented out of particular practices that we have a role in shaping and through which we are shaped

(Barad, 2007, p. 390)

Barad's observation reflects much of Bateson's earlier message to us: we are both part of the environment and shape the environment, which, in turn, shapes us. How our practices shape our world requires responsibility and the sort of wisdom that emerges from a systemic, cybernetic epistemology instead of the short-term solutions of conscious purpose and decontextualised thinking.

We are living in increasingly precarious and troubling times (Tsing, 2015). It is evident that a crisis is with us. Indeed, as Simon (2021) has suggested, we are in a panmorphic crisis echoing Bateson's warnings about our hope of survival.

This state of flux offers both opportunities and threats; we now occupy a liminal space - a place of 
potential and becoming on the one hand, but of environmental catastrophe and the loss of human and non-human life on the other. Liminality is familiar to Jungian psychologists; not one place nor another, but somewhere in between. Ethnographers think of the liminal in the situation of a researcher, separated from their own culture, but at the same time apart from the culture of interest. Systemic practitioners do this all the time. We use phrases like "not knowing" (Anderson and Goolishian, 1992) or "safe uncertainty" (Mason, 1993) to describe the liminality that is part of our practice. It may be found in the session where time flew by, where you were all so engrossed in the conversation and yet felt something, almost impossible to articulate, beginning to shift, or times when a subjugated narrative begins to emerge, or when a metaphor for change begins to form in your mind.

We are responsible for using this space (what little there may be left of it) wisely and taking responsibility in this time of urgency. There have been occasions when I've been trying to repair a broken garage door (that inevitably broke at a time when I really needed it working - isn't that always the case?) or assemble a complicated bit of furniture for myself or one of my children, where I've become frustrated and felt like an upset teenager who wished that my dad, or someone else (anyone!), would materialise and sort it out for me. A moment of quiet reflection invariably leads me back to the realisation that it is down to me. I have to get on with the job myself. I wonder how true this is for all of us, to an extent, wishing someone would come and rescue us, help fix the problem, the mess, and take away our frustration. But, ultimately, it is down to me, to you - us, to take responsibility, not necessarily for creating the mess we are in, but in co-creating routes out of it.

\section{Taking responsibility and becoming an activist}

Taking responsibility within this liminal space at the brink of either healing or disaster may require us to make trouble. As Haraway observes, "Our task is to make trouble, to stir up potent response to devastating events, as well as to settle troubled waters and rebuild quiet places" (Haraway, 2016, p. 1.) As we rediscover the relevance and wisdom of Bateson's cybernetic epistemology and appreciate the threads of his thinking (re)emerging in posthumanities that decentre humans, our discipline already has the benefit of being able to think (and act) systemically. Systemic thinkers are positioned to both make trouble and to create quiet spaces or even the sanctuaries described by Bayo Akomelafe (2020). The Norwegian philosopher and ecologist Arne Naess recognised that, although individually we might not be able to save the world, we still need to be active.

The remedy (or psychotherapy) against sadness caused by the world's misery is to do something about it. I shall refrain from mentioning Florence Nightingale, but let me note that Gandhi loved to care for, wash, and massage lepers; he simply enjoyed it. It is very common to find those who constantly deal with extreme misery to be more than usually cheerful. According to Spinoza, the power of an individual is infinitely small compared with that of the entire universe, so we must not expect to save the whole world. The main point-which is built into the basic conceptual framework of Spinoza's philosophy-is that of activeness

(Naess, 2008, p. 125)

Taking the lead from Naess and answering Bateson's earlier call to therapists, I would argue that we begin to think of ourselves as systemic activists rather than systemic therapists or practitioners. No 
longer confined to clinics, but crossing boundaries into our communities, local woodlands, and wilderness spaces. As systemic activists, we can redefine our attachments and connections, recognise and listen to a multiplicity of voices, human and otherwise, as we shift from being postmodern to becoming posthuman, as Rosi Braidotti tells us:

'We' are immanent to, which means intrinsically connected to, the very conditions we are also critical of. The posthuman convergence is a shared trait of our historical moment, but it is not at all clear whose crisis this actually is. Because we cannot speak of an undifferentiated humanity (or an undifferentiated 'we') that is allegedly sharing in a common condition of both technological mediation and crisis and extinction, extra work is required of critical thinkers... An immanent, posthuman project assumes that all matter or substance is one and immanent to itself. This means that the posthuman subject asserts the material totality of and interconnection with all living things.

(Braidotti, 2019, p. 54)

Reading the quote above, I can't help but be reminded of Bateson's cybernetic epistemology - where context is everything - and we are part of it. As systemic thinkers, practitioners and activists, we are undoubtedly well placed to not only redefine our senses of attachment and connection but to invite others to participate in this journey of healing and transformation. There is as much cause for hope as there is for despair, but this window will not and cannot last long. We can become nomads, not fixed to one way of looking at the world, but travelling with other thinkers and practitioners - not just from our discipline - and, most importantly, with the people we serve. We have individual and collective responsibilities to challenge the individualisation of distress created by the structural violence of capitalism, patriarchy and necro-politics. We have individual and collective responsibilities to challenge colonisation, racism, sexism, and the othering of our kin, both human and otherwise. We have individual and collective responsibilities to respond to the unfolding climate crisis. And we don't have much time - this is urgent.

How we do this, given that all of us are different, will depend on each one of us to take responsibility in our own ways, and as Braidotti notes, "we-are-in-this-together-but-we-are not-one-and-the-same" (2019, p. 165).

Becoming a systemic activist in Bateson's footsteps will require considerable thought and effort. We need to consider the wider loops of our well-intentioned choices, which will inevitably present us with ethical dilemmas. Not only can we make changes in our personal lives, but what changes to how we work might address the many critical changes and situate all the participants in therapy in interwoven wider systems risking and at risk environment? As systemic activists, we can make (or push for, depending on the context in which we work) changes to our working practices to limit the environmental impact. For example, online work reduces the need for travel and transportation. We might consider including "Ecology" as one of the Social GGRRAAACCEEESSS (Burnham, 2013) and talk with the families we support about how ecological concerns may impact them all. It is worth bearing in mind that children and young people, in particular, are becoming very anxious about their future and the future of the planet as we currently know it (Pihkala, 2018). This is far from an exhaustive list, and I hope readers will consider other ways to become systemic activists and share their ideas with others.

If our collaborations in our work do not reflect the changes needed in the wider world, then we are 
kidding ourselves that we are agents of change and that we are still innovators of theories of change.

The concept of isomorphism suggests that it is important for therapists to model the change they wish to see in their systems. As therapists, we are committed to promoting healing and transformation in the lives of our clients, but that means we are ideally also a part of healing and transforming the world within which we all exist

(Laszloffy and Davis, 2019, p. 181)

Healing and transforming our own lives and those of our clients cannot happen on a planet that is no longer able to sustain us. This is a crisis, and we do not have much time to start to think very differently about ourselves and our world and to reorientate and decentre ourselves.

\section{Acknowledgements}

As well as Lorna Edwards and others, I am particularly grateful to my friend and supervisor, Gail Simon, for her encouragement and for introducing me to posthumanities as an emergent field of enquiry based on the convergence of posthumanism and post-anthropocentrism.

\section{References}

Akomolafe, Bayo (2020). Coming Down to Earth: Sanctuary as Spiritual Companionship in a Time of Hopelessness and Climate Chaos. https://bayoakomolafe.net/project/coming-down-to-earth-sanctuary-asspiritual-companionship-in-a-time-of-hopelessness-and-climate-chaos/

Anderson, Harlene, \& Goolishian, Harold (1992). The client is the expert: A not-knowing approach to therapy. In S. McNamee \& K. J. Gergen (Eds.), Therapy as social construction. (pp. 25-39). London: Sage Publications, Inc.

Auerswald, Edgar. H. (1968). Interdisciplinary versus Ecological Approach. Family Process, 7(2), 202-215. https://doi.org/10.1111/j.1545-5300.1968.00202.x

Auerswald, Edgar. H. (1971). Families, change, and the ecological perspective. Family Process, 10(3), 263-280. https://doi.org/10.1111/j.1545-5300.1971.00263.x

Auerswald, Edgar. H. (1987). Epistemological Confusion in Family Therapy and Research. Family Process, 26(3), 317-330. https://doi.org/10.1111/j.1545-5300.1987.00317.x

Barad, Karen (2007). Meeting the universe halfway. Durham NC: Duke University Press.

Bateson, Gregory (1935). 199. Culture Contact and Schismogenesis. Man. 35, 178-183. https://doi.org/10.2307/2789408

Bateson, Gregory, Jackson, Don, Haley, Jay \& Weakland, John (1956). Toward a Theory of Schizophrenia. Behavioral Science 1(4): 251-254. https://doi.org/10.1002/bs.3830010402

Bateson, Gregory (1972). Steps to an Ecology of Mind. San Francisco, CA: Chandler Pub. Co.

Bateson, Gregory (1977). Afterword. In Brockman (ed.) About Bateson. New York: E. P. Dutton.

Bateson, Gregory (1991). In Donaldson, Rodney E. (ed.) A Sacred Unity: Further Steps to an Ecology of Mind. New York: Hampton Press. 
Bateson, Gregory \& Bateson, Mary Catherine (2005). [First published 1987]. Angels Fear: Towards an Epistemology of the Sacred. New York: Hampton Press.

Braidotti, Rosi \& Bignall, Simone (2019). Posthuman Ecologies: Complexity and Process after Deleuze. London: Rowman \& Littlefield.

Braidotti, Rosi (2019). Posthuman Knowledge. Cambridge: Polity.

Burnham, John (2013). Developments in Social GGRRAAACCEEESSS: visible-invisible, voiced-unvoiced. In Krause, Inga (Ed.), Cultural Reflexivity. London: Karnac.

Deleuze, Gilles \& Guattari, Félix (1987). A Thousand Plateaus. Minneapolis: University of Minnesota Press

Featherstone, Valerie (1996). A feminist critique of family therapy. Counselling Psychology Quarterly, 9(1), 1523. https://doi.org/10.1080/09515079608256349

Ginsberg, Allen (2007). Collected Poems 1947-1997. Harper Perennial Modern Classics.

Haraway, Donna (2016). Staying with the Trouble: Making Kin in the Chthulucene. Durham, NC: Duke University Press.

IPCC, 2021: Summary for Policymakers. In: Climate Change 2021: The Physical Science Basis. Contribution of Working Group I to the Sixth Assessment Report of the Intergovernmental Panel on Climate Change [MassonDelmotte, V., P. Zhai, A. Pirani, S. L. Connors, C. Péan, S. Berger, N. Caud, Y. Chen, L. Goldfarb, M. I. Gomis, M. Huang, K. Leitzell, E. Lonnoy, J.B.R. Matthews, T. K. Maycock, T. Waterfield, O. Yelekçi, R. Yu and B. Zhou (eds.)]. Cambridge University Press. In Press.

Laszloffy, Tracey (2009). Remembering the Pattern that Connects: Toward an Eco-Informed MFT. Contemporary Family Therapy, 31(3),222-236. https://doi.org/10.1007/s10591-009-9092-8

Laszloffy, Tracey and Davis, Sean (2019). Nurturing nature: Exploring ecological self-of-the-therapist issues. Journal of Marital and Family Therapy, 45(1), 176-185. https://doi.org/10.1111/jmft.12312

Laszloffy, Tracey and Twist, Markie (2019). Eco-Informed Practice Family Therapy in an Age of Ecological Peril. AFTA Springer Briefs in Family Therapy.

Mason, Barry (1993). Towards a Position of Safe Uncertainty. Human Systems: The Journal of Systemic Consultation and Management, 4, 189-200.

Mbembe, Achille (2003). Necropolitics. Public Culture, 15(1), 11-40.

Naess, Arne (2008). Ecology of Wisdom: Writings by Arne Naess. Edited by Alan Drengson and Bill Devall. Berkeley, CA: Counterpoint.

Pihkala, Panu (2018). Eco-Anxiety, Tragedy, And Hope: Psychological And Spiritual Dimensions Of Climate Change. Zygon, 53 (2) 545-569. https://doi.org/10.1111/zygo.12407

Shaw, Robert (2015). Bringing Deleuze and Guattari down to Earth through Gregory Bateson: Plateaus, Rhizomes and Ecosophical Subjectivity. Theory, Culture \& Society, 32(7-8), 151-171.

https://doi.org/10.1177/0263276414524451

Simon, Gail \& Salter, Leah K. (2019). Transmaterial Worlding. Beyond Human Systems. Murmurations: Journal of Transformative Systemic Practice, 2(2), 1-17. https://doi.org/10.28963/2.2.2

Simon, Gail (2021). Panmorphic Crisis: Cultural Rupture and Systemic Change. Feedback Journal of the Family Therapy Association Ireland, Summer 2021, 17 - 32.

Tsing, Anna (2015). The Mushroom at the End of the World. Princeton, NJ: Princeton University Press. 


\section{Author}

Hugh Palmer, MSc, is an independent systemic psychotherapist, trainer and consultant, based in the East Riding of Yorkshire.

E-mail: hugh.palmer@sky.com

URL: https://hugh-palmer-therapy.com

\section{Citation}

Palmer, Hugh (2021). Where did the Eco go in systemic practice? Murmurations: Journal of Transformative Systemic Practice, 4(1), 1-12. https://doi.org/10.28963/4.1.2 